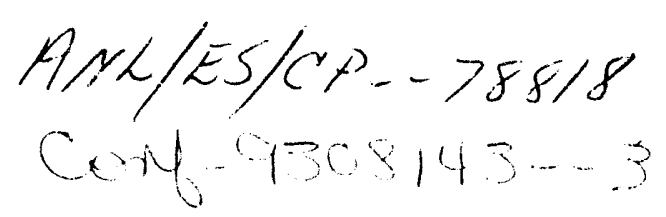

\title{
Some Evidence on Determinants of Fuel Econo.uly as a Function of Driving Cycle and Test Type
}

1. Danilo J. Santini

2. John Anderson
Argonne National Laboratory

Argonne National Laboratory

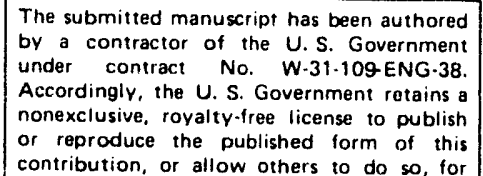

\section{तECEIV \\ AUG 261993 \\ OSTI}

\section{DISCLAIMER}

This report was prepared as an account of work sponsored by ali agency of the United States Government. Neither the Urited States Gnvernment nor any agency thereof, nor any of their employees, makes any warranty, express or implied, or assumes any legal liability or responsibility for the accurac $\%$, completeness, or usefulness of any information, apparatus, product, or process disclosed, or represents that its use would not infringe privaiely owned rights. Reference herein to any specific commercial product, process, or service by trade name, trademark, manufacturer, or otherwise does not necessarily constitute or imply its endorsement, recommendation, or favoring by the United States Government or any agency thereof. The views and opinions of authors expressed herein do not necessarily state or reflect those of the United States Government or any agency thereof. 


\section{ABSTRACT}

Statistical methods are used with 107 vehicles whose fuel economy was presented and reported for five test types in a single publication by Consumers Union (CU) for 1986-1988 vehicles. Standard loglinear statistical formulations (i.e., multiplicative models of interactions) are used with data from this and supplementary sources to develop coefficients estimating the percent fuel economy gain per percent change in engine/vehicle design characteristic. The coefficients are developed for the five different test conditions evaluated by CU and are compared with each other on the basis of attributes of the tests. The insights of engineering models are used to develop expectations regarding the shift in size of coefficients as driving cycles change. For the effects of weight reduction, a range of coefficients is estimated whose high and low values are remarkably consistent with the range of values developed by nine sources cited in the 1992 National Academy of Sciences (NAS) study, "Alitomotive Fuel Economy". In both the engineering models and the staustical model, the effect of weight is estimated to be higher in urban driving than in highway driving. For two test categories - field tests and dynamometer tests - the benefits of weight reduction are statistically estimated to be greatest in urban driving conditions. The effect of weight in the statistical model is estimated to be greater than in the previously developed engineering models, when terms including weight are estimated to vary due to changes in weight. Prior engineering model equations do not write weight into the terms explaining fuel consumption during idle and unpowered deceleration (predominantly braking). The effect on idle fuel flow rate of designing vehicles to hold performance roughly constant by maintaining power per kilogram and/or displacement per kilogram is examined, and its implication for the size of the weight effect is simply approximated from Sovran's 1983 engineering model results. The fuel-economy-decreasing effect of the desire for performance is estimated to be somewhat larger in the statistical analysis than in the NAS study, when engine technology is held constant.

\section{INTRODUCTION}

Fuel economy studies of the effects of various design changes in the gasoline vehicle typically develop point estimates for the percentage improvement that will be achieved, generally providing estimates for the dynamometerbased Federal Test Procedure (FTP) and Highway Fuel Economy Tes! (HFET) test. In the recent National Academy of Sciences (NAS) study of the determinants of fuel economy, there were a wide range of estimates of the effects of changes in vehicle and engine attributes on fuel economy (1). Many of the study's tables preserted estimates of the percentage change in fuel economy resulting from implementation of a particular technology or design isption. In Table B-1 of the NAS study, for example, there were nine different estimates of the percent change in fuel economy arising from a $10 \%$ reduction in vehicle weight, and these estimates ranged from 5\% to $9.1 \%$. This is equivalent to a 0.5 to $0.91 \%$ change in fuel economy per $1 \%$ change in weight. As this paper and several prior papers illustrate, there are very good reasons that the estimated effect of weight varies (2-5). In this paper, the, change in fuel economy in response to a one percent change in vehicle design value will be referred to as the elasticity of response of fuel economy to the design value (this is analogous to the "influence coefficient" estimated by Sovran and Bohn [2] and by Sovran [3]). For the effects of changes in performance capability, from Table 7-6 of the NAS study, it is possible to construct 14 implied elasticity estimates, ranging from an elasticity of -0.09 to -0.15 for the response of fuel economy to a one percent performance increase (expressed in terms of change in power per kilogram). These estimates ranged from -0.10 to -0.15 for cars and -0.09 to -0.12 for light trucks. Engine improvements in the NAS study were listed by technology, including such categories as a compression ratio increase, changing from two to four valves per cylinder, and changing from single-point fuel injection to multipoint fuel injection.

GENERAL METHOD - This study provides additional estimates of what economists have called elasticity and what Sovran and Bohn call "influence coefficients" for many of the potential fuel-economy-enhancing vehicle technology/design options addressed by the NAS study. In particular, it examines the likely origins of at least some of the NAS estimates of influence coefficients for weight and for aerodynamics. It examines a range of possible weight and aerodynamic improvement elasticities that can be derived from selected engineering models and compares them to elasticities that are developed in this paper through statistical methods. These estimates are, in turn, compared to those presented in the NAS 
study. The presentation is intended to help illustrate how the numerous NAS elasticity estimates can be generated by different methods available from the literature. The primary cause of variation in elasticities examined in this paper are driving cycles. Five driving cycles are examined, two of which are from EPA dynamometer-based certification tests. The paper also examines the elasticity of response of fuel economy to several other vehicle technology/design changes, but these are a secondary purpose of the analysis. The primary purpose for including the other factors in this analysis is to eliminate statistical bias in the estimates generated for weight and aerodynamics. Statistical theory indicates that an estimate of the influence of a single variable acting within a system influenced by many interacting variables cannot be properly ascertained unless the influence of all important variables are accounted for. In statistical terms, the estimates of the elasticities of fuel economy in response to weight and aerodynamic drag would be biased unless the influence of other important attributes such as performance capability, engine efficiency, gearing (engine and driveline rotations per mile), type of transmission, and tire design are accounted for in an appropriately designed multivariate regression. It is common in statistical analysis to have imperfect variables. The second best solution for statisticians is to select proxy variables capable of providing some measurement of the desired attribute. In engineering models, the engineer will resort to theory and idealized mathematical descriptions of likely relationships in the absence of statistical/experimental information. Often subsequent techniques and statistical evaluation will cause the revision of the partially idealized engineering model. After comparison of the elasticities estimated in the statistical models in this paper with those developed in the engineering models, arguments are presented in favor of the statistical results, with a recommendation for revisions of the prior engineering models which may largely eliminate the differences in weight and aerodynamics elasticities developed by the two methods.

In Sovran's 1983 analysis, he focuses heavily on the effect of three attributes: weight, drag area (frontal area, A, times coefficient of drag, $C_{d}$ ), and tire rolling resistance. He shows that feasible rolling resistance changes have the smallest possible variability among the three. In the regression analysis discussed below, we are able to include weight and surrogates for the effects of frontal area and tire design. We also use a crude estimator of probable variation in $\mathrm{C}_{\mathrm{d}}$ by assuming that trucks have a significantly different $C_{d}$ value than cars. Sovran includes engine efficiency and driveline efficiency in his conceptual equations, but holds them constant at approximated average values when estimating influence coefficients for weight, aerodynamics, and rolling resistance. We include engine "technology sets" in the regression to control for the effects of engine efficiency. Gearing has an influence on the number of engine and drivetrain revolutions per kilometer, and therefore on frictional losses. Thus, the use of a gearing variable helps control for the variation in both in-use engine and driveline efficiency. The use of a dummy variable to distinguish between autornatic and stick transmissions helps control for some of the important in-use variation in driveline efficiency. Sovran does not include any effect of performance capability in his engineering model, implicitly including only the power necessary to meet the specified driving cycle. An and Ross include engine volume as a determinant of idle fuel consumption, but Sovran simply uses an average value for an unspecified set of sampled vehicles. Both Sovran and An and
Ross treat idle fuel flow primarily as a function of engine volume (displacement). For a constant technology engine, assuming that peak power per unit of volume is approximately constant, more peak power will lead to more engine volume and more fuel consumption during idle and unpowered deceleration (a condition where Sovran assumed idle fuel flow rates). We control for the effect of variation in peak power capability on fuel consumption by including power per kilogram. Regressions which tested for the effect of engine volume were tested, but engine volume proved to be insignificant after the above variables were included. We note, however, that (In of) engine volume was more highly correlated with (In of) vehicle weight $(r=0.88)$ than was any other pair of variables in the data set. A critical point in the closing of the paper involves the importance of specifying the desired (or effective) design relationship between vehicle weight and engine volume in future engineering models.

BACKGROUND - A concern of traffic planners, air quality analysts, and those assessing on-road vs. EPA test fuel consumption is the long-term effect of increases in congestion. Past increases in congestion (6) are anticipated to continue to worsen (7-9), and are considered to be a justification for a significant increase in spending on "Smart Highways" (10). The consequences of increased congestion are increased emissions per kilr meter of travel, increased fuel consumption per kilometer of travel, and increased losses of valuable labor hours of time. An alternative approach to trying to eliminate congestion is to try to better cope with it. Wang and Santini (11), for example, have recently illustrated the increase in the relative emissions and energy consumption advantage of electric vehicles (EVs) when driven in congested conditions. The projected per kilometer advantage of EVs is greatest in the three driving cycles whose average speeds are less than the FTP. The study involves a comparison of projected late 1990s EVs with a moderately improved gasoline vehicle of comparable interior volume. Although Ford and Chrysler are developing EVs which rely heavily on existing vehicle platforms, General Motors has emphasized a ground-up approach in its Impact EV program. A very significant part of the GM program has been to reduce the weight of the EV. At least one question which arises for many analysts is what would the effect of such a reduction in weight have on the fuel consumption and emissions of a gasoline vehicle (12). For those charged with the evaluation of advanced and altematively fueled vehicles such as electrics, an important consideration is how much will the gasoline vehicle improve - that is how far will the target move as the advanced vehicle is developed?

Since the EV will have a greater advantage in congested conditions, one question is how can a gasoline vehicle be altered to diminish the EV advantages? This analysis was undertaken in part to address that question, particularly with respect to low-speed fuel consumption. It has a bearing not only on the ability of the gasoline vehicle to keep an EV out of the marketplace, but also its ability to keep a hybrid vehicle out. Hybrids are also anticipated to have a greater comparative efficiency advantage compared to gasoline when driven in congested conditions. Given the increasing interest in the effects of congestion, there are efforts underway to more precisely model the effects of congestion on fuel consumption, using engineering approximations $(4,5)$, or statistical evaluations (13). The interest in the effects of on-road driving conditions relative to EPA certification tests is not new (14), nor is the interest in EVs as a way of offseuing the effects of the worst congestion. Nevertheless the Advanced Battery 
Consortium, expanded EV research, and the regulatory schedule for 1998 introduction of "zero emissions vehicles" (i.e., EVs) in some states does indicate that the gasoline vehicle will have more difficulty than in the past in keeping EVs from entering the market. Further, the problem of congestion and consequent poor urban air quality is not only a U.S. problem but can be described as horrendous in some major metropolitan areas of the world.

\section{ILLUSTRATIONS BASED ON ENGINEERING} PRESENTATIONS - MacCready is one advocate of the benefits of electric and hybrid vehicles (15). In discussing those benefits, he presents a table illustrating simplified properties of the energy used in driving. He computes the rolling friction, aerodynamic drag, and single-stop kinetic energy loss for a $1,440 \mathrm{~kg}$ car with $135 \mathrm{~kg}$ of passenger load, $2.25 \mathrm{~m}^{2}$ of frontal area (A), 0.3 coefficient of drag $\left(\mathrm{C}_{\mathrm{d}}\right)$, and 0.007 rolling friction coefficient $\left(r_{0}\right)$. (For purposes of comparison, Sovran assumed in his 1983 paper that the $C_{d}$ of a representative car was $0.47, r_{0}$ was 0.009 , and weight was $1,275 \mathrm{~kg}$ ). MacCready uses these numbers to illustrate the comparative effects of these three sources of energy use at a steady 24,48 , and $97 \mathrm{~km} / \mathrm{h}$ followed by a single stop, by using the analogy of height to which the vehicle would have to be lifted in the absence of any other forces to overcome the given source of energy loss. MacCready notes that the effects of aerodynamic drag are independent of weight. The components of energy use discussed by MacCready are essentially the same as those discussed initially by Sovran and Bohn (2). While informative, the MacCready analogy is not realistic in terms of actual driving, since actual driving at 24 and $48 \mathrm{~km} / \mathrm{h}$ average speeds includes kinetic energy loss due to multiple stops and idling energy waste during the time the vehicle is stopped. Further, accessory loads, such as power brakes, power steering, and air conditioning, are ignored. Sovran recognized the shortcoming of his 1981 analysis for those concerned with estimating actual fuel use of a vehicle on the diving cycle, and provided revised estimation methods in 1983 which accounted for idle fuel consumption during stops and unpowered braking and for fuel consumption by accessories. A more recent detailed engineering model which incorporates these and other considerations with a somewhat different approach is presented by An and Ross (5).

Sovran's 1983 paper emphasized the fuel consumption reductions achievable through aerodynamic improvements (3). Aerodynamic drag, independent of weight, is a function of the product of $A, C_{d}$ and velocity ( $v$ ) squared. For convenience, the product $C_{d} A$ is referred to as "drag area". For a vehicle with a given $A$, Sovran estimated that the drag area elasticity of response of EPA highway fuel consumption to reductions in $C_{d}$ or $A$ conld range from 0.43 to 0.62 , depending on the values of $C_{d}$ and $r_{0}$. Elasticity (influence coefficient) values estimated by Sovran drop as $C_{d}$ drops and increase as $r_{0}$ decreases. In other words, when energy losses due to rolling resistance are reduced, the relative share of energy used due to aerodynamic drag goes up. Conversely, as $C_{d}$ is reduced, the value of each added percent reduction in $\mathrm{C}_{d}$ is reduced since energy lossec due to drag now constitute a smaller share of total energy use. Sovran's estimated drag area elasticity values for driving on the EPA urban cycle varied from 0.13 to 0.23 . Sovran calculated an equivalent percentage mass reduction needed to match a given percentage reduction in $C_{d}$, emphasizing the greater ease of achieving fuel economy gains through improvements in aerodynamics.
Sovran's work may have been influential, given the fact that mean rated EPA highway passenger-car fuel economy from 1983 to 1991 improved at $1.3 \%$ per year, about double the $0.7 \%$ annual rate for city fuel economy (16). In the prior eight years, the rate for highway fuel economy was $6.7 \%$, in comparison with $6.1 \%$ for city fuel economy. For the entire 1975-1991 period, passenger-car highway fuel economy rose by $85 \%$, while city fuel economy rose by $71 \%$. Truck highway fuel economy rose by $62 \%$, while city fuel economy rose by $48 \%$. Clearly, manufacturers have had more trouble increasing fuel economy in city driving conditions than in highway conditions, or they have adopted strategies which unintentionally have this effect. Incorrectly high estimates of the effectiveness of aerodynamic improvements could have this effect.

In Table 1, we use some ad hoc approximations to estimate the effects of most of the major sources of driving cycle energy use identified by Sovran in 1983 (fuel consumption during unpowered deceleration is not included). We have assumed 15 seconds per stop, instantaneous acceleration and deceleration (no idling during deceleration), idling energy used to overcome engine friction per second as equal to $50 \%$ of energy required per second at a steady $48 \mathrm{~km} / \mathrm{h}$, and energy needed to meet accessory loads at $67 \%$ of idling energy use per second. The accessory load assumption is appropriate for an air conditioner, but for power steering or power brakes a different relationship would be desirable. Accessory load for power brakes would increase with the number of stops and the cruise speed. The number of stops per kilometer are taken from Fig. 32 of EPA's Passenger Car Fuel Economy: EPA and Road (14). Instead of steady 24 and $48 \mathrm{~km} / \mathrm{h}$ speeds, we back out a necessary cruise speed to offset the time lost in stops, in order to maintain the desired average speed. The result is only an illustration intended to develop, for readers of this paper, a rough intuition about the composition of causes of energy loss in different driving cycles, without the level of tetail used by Sovran and by An and Ross. We break out the contributions according to those which are not affected by weight and those which are. The uses of energy not affected by weight are further broken down into those affected by body design (aerodynamic drag) and those determined largely by a measure of time of the activity. Idling energy use per kilometer is related to time stopped per kilometer, and air conditioning energy use to time in the vehicle per kilometer. Both are positive functions of number of stops per kilometer.

An and Ross also compute a breakdown of driving cycle energy consumption for seven driving cycles according to the categories listed in Table 1. However, An and Ross (their Table 9); also include "engine-friction" energy losses attributable to all portions of the driving cycle in total (see discussion in next section). Ideally, these losses would be separately attributed to each of the categories. To construct a breakdown comparable to that presented in Table 1, we deleted An and Ross' engine friction column percentages, and recomputed the shares according to the breakdown above. These are shown in Table 2.

Both Sovran and An and Ross write equations which include the mass of the vehicle in the terms accounting for the effects of rolling resistance and accumulation of kinetic energy (acceleration). Sovran argues that idle fuel consumption can reasonably be approximated by a constant, after stating that an "approximately linear variation of fuel rate with engine displacement was clearly evident" for vehicles examined. An and Ross write terms for which idle fuel flow rate is a function 
of engine displacement. Note that neither the Sovran or the An and Ross models indicate any relationship between mass of the vehicle and idle fuel flow rate. This point will be revisited after examining the implications for fuel consumption of varying the mass of the vehicle according to the formulas presented by Sovran and by An and Ross. In other words, we will examine what percentage change in fuel consumption would arise in these models if a one percent change in mass of the vehicle is entered in those terms of the equation where mass is included. The presentation of categories in Tables 1 and 2 is consistent with the conventions used by Sovran, MacCready, and An and Ross, all of which explicitly write that weight influences only the portions of the driving cycle where kinetic energy is accumulated and where rolling resistance is overcome.

Sovran's simplified model breaks down energy consumption into four major categories in his equation 11 . These are energy losses due to (1) tractive energy used during the powered portions of the driving cycle, say TR, (2) losses due to accessories, AC, (3) losses during idling, ID, and (4) losses during braking, BR. Tractive energy losses are divided into three components due to (1) mass, $M$, times $r_{0}$, (2) $C_{d}$ times A, and (3) M. These components are, in effect, multiplied by constants specific to the driving cycle and to the engine and drivetrain assumed. Let us call these $u_{c}, v_{c}$, and $w_{c}$ for convenience. The term $c$ denotes the specific driving cycle and should also be attached to AC, ID, and BR. Let total energy for a given driving cycle be $\mathrm{ET}_{\mathrm{c}}$. Then total energy used in a given driving cycle is

$$
\begin{aligned}
E T_{c}= & u_{c} \cdot M \cdot r_{o}+w_{c} \cdot M+v_{c} \cdot C_{d} A+ \\
& A C_{c}+I D_{c}+B R_{c} .
\end{aligned}
$$

The fractions of energy use due to each component can be estimated by dividing through by $\mathrm{ET}_{\mathrm{c}}$. Sovran's estimated fractional shares for these components van be broken out as shown in Table 3.

It is important to note that Sovran developed numerous plots of relationships among $M, r_{0}$, and $C_{d}$ under the assumption of constant values for $A C_{c}, I D_{c}$, and $B R_{c}$. If we write the average energy for a Sovran vehicle on the EPA urban cycle as $\Omega_{0}$, and the average mass as $M_{0}$, the variability of energy use around the mean value as a function of mass generally $(M)$ is

$$
\begin{aligned}
\Omega_{0}= & M \cdot\left(0.37 / \mathrm{M}_{0}\right) \cdot \Omega_{0}+\mathrm{M} \cdot\left(0.17 / \mathrm{M}_{0}\right) \cdot \Omega_{0}+ \\
& 0.20 \cdot \Omega_{0}+0.10 \cdot \Omega_{0}+0.07 \cdot \Omega_{0}+0.09 \cdot \Omega_{0}
\end{aligned}
$$

or, as

$$
\Omega_{0}=\mathrm{M} \cdot\left(0.54 / \mathrm{M}_{0}\right) \cdot \Omega_{0}+0.46 \cdot \Omega_{0}
$$

A change of energy use due to a change of mass from $M_{0}$ to $\mathrm{M}_{1}$ can be written as

$$
\begin{aligned}
\Omega_{0}-\Omega_{1}= & \left(\mathrm{M}_{0} \cdot\left(0.54 / \mathrm{M}_{0}\right) \cdot \Omega_{0}+0.46 \cdot \Omega_{0}\right)- \\
& \left(\mathrm{M}_{1} \cdot\left(0.54 / \mathrm{M}_{0}\right) \cdot \Omega_{0}+0.46 \cdot \Omega_{0}\right) \\
= & \left(\mathrm{M}_{0}-\mathrm{M}_{1}\right) \cdot\left(0.54 / \mathrm{M}_{0}\right) \cdot \Omega_{0}
\end{aligned}
$$

to get the fractional change in energy use per fractiona! change in $M$, divide through by $\Omega_{0}$ to obtain:

$$
\frac{\Omega_{0}-\Omega_{1}}{\Omega_{0}}=\frac{\left(M_{0}-M_{1}\right) \cdot\left(0.54, M_{0}\right) \cdot \Omega_{0}}{\Omega_{0}}
$$

if $M_{0}-M_{1}=x \cdot M_{0}$, then the fractional change in energy use for an $\mathrm{x}$ unit change in mass is

$$
\frac{\Omega_{0}-\Omega_{1}}{\Omega_{0}}=\mathrm{x} \cdot \mathrm{M}_{0} \cdot\left(0.54 / \mathrm{M}_{0}\right)=0.54 \cdot \mathrm{x}
$$

This exercise, if generalized, illustrates how the share of energy theoretically affected by mass in the engineering equations translates into an "influence coefficient", or elasticity, of response of full consumption to weight, where the influen : coefficient above is 0.54 . For Sovran's highway example, the mass "influence coefficient" would be 0.32 instead of 0.54 (the sum of the first two shares in the EPA Highway row of Table 3 ). The general form of these equations would also translate the acrodynamic drag loss share into an influence coefficient of 0.20 for the EPA Urban cycle and 0.57 for the EPA Highway cycle. Note here that we are illustrating the overall principles by which elasticity estimates emerge through the use of the Sovran reference as a starting point. These are illustrative values which can be varied significantly by the analyst by manipulating the equations presented by Sovran. We are not arguing that the methods used by Sovran to develop the fractions of energy use influenced by mass are correct for the case where engine size and vehicle design is allowed to vary. Sovran addresses some of the considerations concerning the importance of changing engine size and gearing in order to obtain the fuel efficiency gains estimated by his method, but does not consider the effects on his equations of an assumption that engine size and idle fuel flow rate are linked. He discusses the need to resize the engine to maintain efficiency during the portion of the cycle where tractive energy is used.

\section{EXPECTA'TIONS BASED ON ENGINEERING MODELS}

The discussion that follows covers the expected behavior of the variables which have been included in the statistical model below, taking into account the engineering-model-based insights from Tables 1, 2, and 3 when applicable, and taking into account other implications from the engineering models referred to for this analysis.

WEIGHT - The percentages shown at the bottom of Table 1 and in Tables 2 and 3 estimate that weight and idle/accessory loads are far more important in the U.S. (FTP) and other urban driving cycles, while aerodynamic drag dominates in the U.S. Highway cycle and at high steady speeds. Tables 1 and 2 imply that the relative importance of weight reduction peaks in urban driving with a similar average speed to that of the EPA Urban cycle, and drops off for the even more congested cycles used Japan and Europe. Outside the U.S., most test cycles used (T'ble 2) imply that reduction of accessory loads and idle fuel consumption is about as important as reducing the effect of weight on the need to accumulate kinetic energy and to overcome rolling resistance. On the basis of the numbers in Tables 1-3, one would predict that a $1 \%$ change in weight would have a far greater effect in congested U.S. driving conditions than in expressway driving. 
According to Table 2 , a $1 \%$ reduction in weight should result in a $0.59 \%$ increase in fuel economy on the U.S. Urban cycle and a $0.46 \%$ increase in the U.S. Highway cycle. Using Sovran's values for a representative automobile of 1983, coefficients can be netted out of Sovran's Table 1 , by reading off the contribution of aerodynamics from Sovran's Table 2. This method gives Table 3's approximate share of Urban cycle fuel consumption of $54 \%$ for the sum of the kinetic and rolling resistance terms shares and $32 \%$ for Highway cycle fuel consumption. Thus, for a 1983 vehicle, Sovran's estimates indicated that a $1 \%$ reduction in weight would lead to a $0.54 \%$ increase in urban fuel economy and a $0.32 \%$ increase in highway fuel economy. This result is also obtained by using Sovran's typical vehicle values in his equations 33a and 33b. Note that Sovran's values wou!d move toward those of An and Ross if a more aerodynamic 1993 vehicle were substituted for the 1983 vehicle assumed by Sovran. If the $C_{d}$ value is dropped from Sovran's 0.475 to 0.32 , consistent with Sovran's recommendations, the calculated ur uan and highway weight elasticities increase to 0.59 and 0.40 respectively.

AERODYNAMIC DRAG - The percentages of energy use due to aerodynamic drag (body shape) shown in Tables 1 and 2 imply that a $1 \%$ change in $C_{d} \cdot A$ should have a greater effect on fuel economy at higher average driving speed and imply that the coefficient should rise sharply as average speed increases. For the standard vehicle as used by An and Ross for the values which result in Table 2 , a $1 \%$ improvement in $C_{d}$ leads to a $0.14 \%$ increase in EPA Urban fuel economy and a $0.46 \%$ increase in Highway fuel economy. Sovran's 1983 vehicle (Table 3 ) would be estimated to realize a $0.20 \%$ increase in Urban and $0.57 \%$ increase in Highway fuel economy respectively. As for weight, modification of Sovran's equation to update the $C_{d}$ value would move Sovranbased estimates toward those of An and Ross.

ENGINE AND DRIVETRAIN EFFICIENCY - One of the missing factors in Table 1 is the effect of conversion losses in the engine and drivetrain. For those components of energy use which occur while energy is used to move the vehicle (overcoming rolling resistance, accelerating to gain kinetic energy, and pushing against air), the efficiency of the engine and drivetrain will determine how much total original energy in the fuel is required. For idling in neutral (often not the case with automatic transmissions), the efficiency of the drivetrain will not matter. The efficiency of the combustion process in the engine will matter as long as the engine is on, to the extent that engine friction requires energy to overcome. Further, more efficient engines consistently have a higher peak power output per liter. Thus, for a given peak power level, a more efficient engine will be a smaller displacement engine. To the extent that idle fuel consumption is a function of displacement, this will mean that enhanced engine efficiency will lead to lower idle fuel consumption. Similarly, a more efficient engine will use less fuel to run accessories. For a given engine, there will be a region of load and revolutions per minute (rpm) where efficiency will be maximized. At cruise the right gear to get closest to this point can be selected. However, the efficiency at low rpm and low load will generally be well below the optimum efficiency. Consequently, the process of moving though the gears to accelerate from idle to cruise speed will lead to a lowsr average efficiency than will cruising at a steady speed. This effect is not taken into consideration in Table 1. If it were, the share of energy consumption attributable to accumulating kinetic energy by accelerating would rise more for cycles with a greater number of stops per kilometer, and total energy consumption would rise more sharply as average speed declined (and number of stops increased).

This discussion illustrates that engine efficiency can reduce the fuel consumption for all of the components of the drive cycle shown in Table 1, although it does not imply that the effect will be the same in all cases. Nevertheless, a broad approximation that engine efficiency has a multiplicative effect on energy consumption in all driving cycles, including those with significant idling and accessory loads, has some plausibility. An and Ross did not see any need to break out engine friction losses due to components of the driving cycle, grouping all losses into one category. For steady speeds this treatment is obviously appropriate.

We have tested for differences in inherent engine efficiency by collecting information on some technical attributes of engines estimated by others to have a significant effect on engine efficiency (Ref. 1, p. 198).

PERFORMANCE CAPABILITY - Another factor missing from Table 1 is the question of performance capability. Similarly, Sovran and An and Ross have not made an attempt to estimate the effect of providing performance capability well in excess of the driving cycle requirements, which is common in vehicles actually sold. The effect of variation in the rate at which the vehicle could be accelerated was ignored in the engineering references cited and in the computations above. However, if idle fuel consumption is indeed linked to engine displacement, then the selection of a larger displacement engine of a given level of technology would lead to greater fuel consumption at idle. Alternatively (or additionally), if a larger displacement engine has more rubbing surface area than a smaller engine, then frictional losses in the larger engine might be consistently greater, increasing energy consumption relatively evenly through essentially all portions of the driving cycle. An and Ross link idle fuel consumption in part to rpm at idle and estimate that idle speeds for larger engines are lower (5). This would tend to offset any increases in idle energy use due to greater friction. Such a trade-off is likely due to the need for smooth idling operation in smaller engines, leading to higher idle speeds than necessary for functional operation in those engines.

Zero to $97 \mathrm{~km} / \mathrm{h}$ performance capability, as estimated in prior studies, is very well explained by the variable power per kilogram (17). This variable is used here to control for the effects of performance capability in the regressi on model.

AUTOMATIC TRANSMISSIONS - Due to partial engagement at idle, automatic transmissions should cause a greater loss in fuel economy for those driving cycles with a lot of time spent at idle. Since automatic transmissions generally use viscous couplings and do not "lock up" the engine crankshaft and driveline except in high gear (and even then not in all cases), it can be expected that automatics will exhibit significantly lower fuel economy than stick shift transmissions.

GEAR RATIO - As discussed in the engine and drivetrain efficiency section, efficiently overcoming internal engine friction and drivetrain friction is a function of the engine efficiency. However, the amount of friction to be overcome depends in part on how many times per kilometer the engine and drivetrain rotate. More rotations per kilometer mean more friction to be overcome. An and Ross (5), and many others, 
use the $\mathrm{N} / \mathrm{v}$ ratio - the engine speed to vehicle velocity ratio in the top gear of the transmission. This is closely related, in practice, to the product of the axle ratio and the to? gear ratio (overall ratio in top gear). In the statistical sample used here it was found that the $N / v$ ratio and the overall ratio in top gear were so highly correlated as to be indistinguishable from one another. Since the effect of the overall top gear ratio should be a function of what fraction of time per kilometer the vehicle spends in top gear, one might expect the coefficient of this variable to be larger for the higher average speeds, since a greater share of driving time is spent in top gear in those cases.

TIRE DESIGN - Estimates by An and Ross (not shown separately here), imply that reduced rolling resistance will have a greater beneiit at higher average speeds. The percentages of energy loss attributable to rolling resistance also rise with increasing speed according to the estimates in Table 1. Sovran's base values for a representative 1983 vehicle led to estimates of an elasticity of resporise to changes in rolling resistance of 0.17 for urban driving and 0.22 for highway driving (Sovran equations 37a and $37 \mathrm{~b}$ in Ref. 3).

\section{METHOD}

Within the U.S., the availability of fuel economy test data under test cycles different from the U.S. EPA FTP and Highway cycles is rather limited. EPA does conduct testing of vehicles under different cycles for purposes of constructing the Mobile series of emission models. Possibly that data could be used to calibrate engineering models such as that by An and Ross, so that the change in effect of altering vehicle design characteristics as a function of driving cycle could be estimated. Another source of data, which is used by many consumers in their evaluation of which vehicle to buy, is the test information collected by Consumers Union and published in Consumer Reports. This test data includes three driving "cycles" different from the EPA vehicle dynamometer-based FTP and Highway cycles. The reported fuel economy from these tests is developed from on-road testing of the vehicles rather than dynamometer-based testing. Thus, in addition to potentially contributing to the understanding of the variation in determinants of fuel economy as a function of driving cycle, the use of the Consumers Union test data might reveal some systematic differences in estimated efrects using on-road rather than dynamometer tests.

In this study we use a data base which was convenient to assemble. In 1989 Consumers Union published a summary of its test results for the model years 1986-1988 in a used car buying guide (18). In this publication, Consumers Union provides enough technical detail on vehicles to conduct a statistical examination of the major determinants of fuel economy under field conditions and under dynamometer test conditions. A data base of 107 vehicles has been assembled from the Consumers Union test and vehicle specifications information. The sample is dominated by passenger cars. However, four pickup trucks, four 4 wd sport-utility vehicles, and eight minivans are included. The Consumers Union fuel economy tests include a $1.6 \mathrm{~km}$ simulated city-traffic circuit (CUCity), a $6.4 \mathrm{~km}$ stretch of highway at $88 \mathrm{~km} / \mathrm{h}$ (CU88kph), and a $314 \mathrm{~km}$ trip (CUHighway). Although we requested information on the variable-speed driving cycles, such as average speed, Consumers Union did not provide such detail. However, Consumers Union did recently publish some details concerning its City cycle (19). Our examination of the information for that cycle, in comparison to that for the EPA Urban cycle, indicated 1.9 stops per kilometer for the CUCity cycle vs. 1.5 for the EPA Urban cycle. The peak speeds of the CUCity cycle, typically at $64 \mathrm{~km} / \mathrm{h}$, are generally higher than those for the EPA Urban cycle (20), so average acceleration rates in the CUCity cycle are probably somewhat higher. Assuming the same duration of time per stop for the CUCity and EPA Urban cycles, we estimated that the CUCity cycle had a slightly lower average speed. We have ordered the presentation of the test results on the basis of the average fuel economy results for the five tests. The CUCity fuel economy was consistently lowest, probably as a result of more idling time per kilometer and brisker rates of acceleration than for the EPA Urban cycle. The CUHighway fuel economy test results were often close to the EPAHighway results, but were generally slightly higher. The best fuel economy was for the CU88kph steady-speed test.

\section{VARIABLES}

\section{Consumers Union Input Variables Used in Presented Model}

$M P G_{d}=$ reported fuel economy for driving cycle $d$, where $d$ is one of the five cycles

$$
\begin{aligned}
H P & =\text { net power } \\
L & =\text { displacement in liters } \\
C W & =\text { curb weight } \\
W d & =\text { width } \\
H t & =\text { height from door top to ground } \\
G & =\text { overall gear ratio in high gear } \\
T & =\text { transmission type (= } 0 \text { if stick and } 1 \text { if automatic) } \\
\mathrm{P} & =\text { tire aspect ratio }
\end{aligned}
$$

Truck = truck dummy variable: 1 if a sport utility vehicle or pickup truck, 0 otherwise

Engine Technology Variables Collected From Other Sources (Automotive News, Chiltons)

$$
\begin{gathered}
\mathrm{F}=\text { fuel injection }=1, \text { carburetion }=0 \\
\mathrm{~V}=\text { number of valves per cylinder }(2,3, \text { or } 4) \\
\mathrm{OHC}=\text { overhead camshaft }=1, \text { pushrod }=0 \\
\text { Turbo }=\text { turbocharged }=1 \text {, naturally aspirated }=0 \\
\text { Derived Input Variables Used in Presented Model } \\
\mathrm{HP} / \mathrm{CW}=\begin{array}{l}
\text { power per unit of curb weight ( a performance } \\
\text { capability surrogate ) }
\end{array} \\
\text { Area }=\begin{array}{l}
\text { In of the quantity Wd times } \mathrm{Ht} \text { (used as a surrogate } \\
\text { for frontal area }- \text { coefficient of drag }\left[\mathrm{C}_{\mathrm{d}}\right] \text { not } \\
\text { available) }
\end{array}
\end{gathered}
$$


TArea $=$ zero for all vehicles other than pickup trucks and sport utility vehicles, Truck times Area otherwise (a surrogate to allow testing of the expectation that $C_{d}$ for pickups and sport utilities is higher than for cars)

TS1 = Engine technology set 1 - carbureted, pushrod, 2 -valve per cylinder engines $=1$, others $=0$ (4 vehicle types)

TS2 = Engine technology set 2 - fuel-injected, pushrod, 2 -valve per cylinder engines not turbocharged $=1$, others $=0$ (28 vehicle types)

TS3 = Engine technology set 3 - carbureted or fuelinjected, overhead-camshaft, 2-valve per cylinder engines not turbocharged $=1$, others $=0(56$ vehicle types)

TS4 = Engine technology set 4 - carbureted, overheadcamshaft, 3 or 4 valve per cylinder engines not turbocharged $=1$, others $=0$ ( 2 vehicle types)

TS5 = Engine technology set 5 -fuel-injected, overheadcamshaft, 3-or 4 valve per cylinder engines not turbocharged $=1$, others $=0$ (7 vehicle types)

TS6 = Engine technology set 6 - fuei-injected, overheadcamshaft, 2-valve per cylinder turbocharged engines $=1$, others $=0$ (5 vehicle types)

TS7 = Engine technology set 7 - fuel-injected, overheadcamshaft, 4-valve per cylinder turbocharged engines $=1$, others $=0(1$ vehicle type $)$

The TArea variable will be recognized as a multiplicative dummy variable (Ref. 21 , pp. 157-8) which can be used to test for a different response of fuel economy to the frontal area of pickup trucks and sport utility vehicles. If the TArea variable is included in an equation with the Area variable, the coefficient for the Area variable will measure the effect of Area on fuel economy for all vehicles other than "trucks" (sport utility vehicles and pickup trucks), while the TArea coefficient will measure the difference between the Area coefficient for all other vehicles and the Area coefficient for trucks. If the TArea coefficient is estimated to be significant, it can be asserted that there is a difference in the response of fuel consumption to truck (frontal) Area than to the (frontal) Area of all other vehicles. Such a difference should exist if the $C_{d}$ for these vehicles is significantly different than for passenger cars and vans. This is the best test we could develop in the absence of $C_{d}$ values. Note that preliminary equations used this technique to separately test for differences of $C_{d}$ for vans, pickup trucks and sport utility vehicles. These experiments indicated that the effect of van frontal area could not be statistically distinguished from that of passenger cars, while the effects for the pickup trucks and sport utility vehicles could not be distinguished from one another. We also used a 0,1 dummy variable to test for differences of the intercept for trucks to see if the effect we measured was incorrectly identified as a difference in aerodynamic response when in fact it was a general difference for pickup trucks and sport utility vehicles. This test failed there was no evidence of a different intercept term for these vehicles.
The engine technology set variables are intercept shift dummy variables, taking on a value of zero or one. Consistent with estimation restrictions, only six of the seven variables can be entered into an equation. The one left out becomes the base value, while all other coefficients represent a measure of whether the tested engine technology is significantly different from the base value. In the tests presented below, TS1 is left out, since it is the oldest and lowest level of engine technology in the data set. The expected signs of the coefficients of TS2 through TS7 are positive. The engine technology set information was collected by examining Chilton's manuals for domestic and foreign cars $(22,23)$ and by consulting the Automotive News Market Data Books for 1986, 1987, and 1988 (24-26).

The engine technology set combinations that we present above are the final combinations that we decided upon. In the course of testing the possible configurations of technology sets, we initially examined a larger number of sets. TS3, TS4, and TS5 include members originally part of two separate sets. The prior sets were grouped together when there seemed to be no significant difference in the estimated coefficients for those separate sets. In the case of TS4 and TS5 the relatively small number of observations also was a consideration. However, this consideration was secondary to the plausibility of the comparative coefficient values. Although TS7 includes only one type of vehicle, it was kept separate because it did have some of the largest coefficient estimates measuring fuel efficiency gain, consistent with theoretical expectations that this engine technology should be the most efficient.

The form of the statistical models tested is a logarithmic, or multiplicative model, such as that developed by Berger, Smith and Andrews (27). In this form of model, each of the included variables is logged, and an additive model is estimated. The resulting coefficients of independent variables are interpreted as the elasticity of response of the dependent variable to the tested independent variable. The presented model is

$$
\begin{aligned}
\ln \left(\mathrm{MPG}_{d}\right)= & a_{0}+\mathrm{a}_{1} \ln (\mathrm{CW})+\mathrm{a}_{2} \ln (\mathrm{HP} / \mathrm{CW})+ \\
& \mathrm{a}_{3} \mathrm{TS} 2+\mathrm{a}_{4} \mathrm{TS} 3+\mathrm{a}_{5} \mathrm{TS} 4+\mathrm{a}_{6} \mathrm{TS} 5+\mathrm{a}_{7} \mathrm{TS} 6+ \\
& \mathrm{a}_{8} \mathrm{TS} 7+\mathrm{a}_{9} \mathrm{~T}+\mathrm{a}_{10} \ln (\mathrm{Gear})+\mathrm{a}_{11} \text { Area }+ \\
& \mathrm{a}_{12} \mathrm{TArea}+\mathrm{a}_{13} \ln (\mathrm{P})+\text { error }
\end{aligned}
$$

(Note that Area and TArea are already presented in In form. Only the TS variables and $\mathrm{T}$ variable are zero/one dummy variables)

The same equation is estimated for each of the five driving cycles. The $a_{1}, a_{2}$, and $a_{10}$ to $a_{13}$ coefficients are interpretable as elasticities. The $a_{3}$ to $a_{8}$ coefficients are interpretable as estimates of whether the engine technology set causes the vehicle to realize significantly better fuel efficiency than if the engine were a carbureted pushrod 2 valve per cylinder engine. The ag coefficient is interpretable as a test whether the intercept term $a_{0}$ is significantly different for automatic-transmission-equipped vehicles than for sticktransmission-equipped vehicles. The $\mathrm{a}_{12}$ coefficient is interpretable as an estimate of whether $C_{d}$ (and therefore net elasticity) for the separate class of vehicles is significantly different from that for passenger cars and vans. To obtain the net elasticity estimate for the effective drag area of pickup trucks or sport utility vehicles, one adds $a_{11}$ and $a_{12}$. 
For purposes of estimation of kilometers per liter, the model above is written as

$$
\begin{aligned}
& M P G=e^{a} 0 \cdot C W^{2} 1 \cdot(H P / C W)^{a 2} \cdot T^{a 9} \\
& \left(\text { Gear) }{ }^{a_{10}} \cdot \text { (Area }\right)^{\left(a_{11}+a_{12} \cdot\right. \text { Truck). }} \\
& \mathrm{P}^{\mathrm{a}} 13 \cdot \mathrm{e}^{\mathrm{a}_{\mathrm{i}} \cdot \mathrm{TSi}}
\end{aligned}
$$

where

$\mathrm{e}=$ natural $\log$

$i=2$ to 7 , depending on engine technology set $\left(a_{i}=0\right.$ if $\left.i=1\right)$.

Although the logarithmic model is preferred for its convenience in directly estimating elasticities (or equivalently, "influence coefficients"), it also happens to be superior statistically to a linear model. The goodness of fit $\left(R^{2}\right)$ of analogous linear models were consistently lower than those for In-ln models tested, and the properties of the residuals were far more well-behaved. The In-ln model consistently eliminated "U-shaped" residual patterns present in the linear models and also reduced or entirely eliminated heteroscedasticity (which only appeared in conjunction with the Area variable before separately breaking out sport utility and pickup trucks).

The results for all 107 vehicles and all five driving cycles are presented in Table 4 . The entries of Table 4 are estimated coefficients and t-statistics.

\section{FINDINGS}

WEIGHT - The elasticity estimates for weight range from -0.49 to -0.95 , in comparison with a range of -0.5 to -0.91 in the NAS study of fuel economy (1). For a given test type (EPA dynamometer or Consumer Reports on-road), the importance of weight declines as average speed increases.

PERFORMANCE - The estimates of elasticity of kilometer per liter with respect to increases in power per kilogram range from -0.05 to -0.30 . This compares to implied elasticities ranging from -0.10 to -0.15 for passenger cars in the NAS study. The sample is dominated by passenger cars, so the comparison with NAS passenger car estimates is most appropriate. While the range of estimates here overlaps with those of the NAS study, the elasticities here are generally higher. However, the NAS study does not say whether or not engine technology was held constant. The elasticity estimates here are for the case where engine technology is held constant. If greater power per kilogram were achieved through an improvement in engine technology, then the elasticities would have to be adjusted for the effects of the new technology. Net elasticities could be estimated to account for this effect. It is possible to both improve fuel economy and performance if a significant jump in engine technology level is achieved. Isolated examples could be cited, including the adoption of General Motors "Quad 4" in some applications. Aside from the low value in the CUCity cycle, there is no pattern to the remaining elasticity estimates, which are all statistically significant.

LNGINE EFFICIENCY - The engine technology set dummy variables are generally estimated to be insignificant. However, for the extreme technologies for which there are a reasonable number of vehicles represented, the differences are consistently estimated to be statistically significant. The percentage differences in the base TSI technology set - the carbureted pushrod, 2-valve per cylinder engines - and in the TS 5 fuel-injected, overhead-camshaft, 3-4 valve per cylinder engines range from 0.11 to 0.17 , and are always statistically significant. For highway driving cycles, the estimated coefficients are more frequently estimated to be statistically significant, than for the two city cycles. This is consistent with Sovran's formulation, where engine efficiency was assumed only to influence tractive energy losses and losses to accessory loads, and not energy use during idling and braking. Given his formulation, the influence of better engine technology should show up more clearly in driving cycles where idling and braking constitute a small fraction of energy use.

Although the coefficients of the fuel-injected, pushrod, 2-valve per cylinder engine technology set are always insignificant, they are always positive and vary over a reasonable range. The NAS study included estimates that adding throttle body fuel injection added from 0.8 to $3.3 \%$ to engines otherwise carbureted, while multipoint fuel injection added from 2.5 to $6.0 \%$. We did not consider our sources reliable enough to distinguish among types of fuel injection. The estimates from Table 4 indicate a range of improvement of 2 to $7 \%$ for the addition of fuel injection to a TS1 engine. In another case, however, we were not able to isolate a positive effect for fuel injection. Technology set TS3 is carbureted or fuel injected because we could not find a significant difference between fuel-injected and carbureted overhead-camshaft engines. This, of course, does not mean that such an effect does not exist, but the data did not allow its identification. In another test for the effect of fuel injection, a comparison of sets TS4 and TS5, most of the results imply an improvement with the use of fuel injection.

The TS3 coefficients can be regarded as estimates of the effect of adding an overhead camshaft to a base pushrod engine. The estimates range from a 2 to a $10 \%$ effect. The NAS study values range from 0.8 to $3.5 \%$.

Comparison of coefficients of turbocharged TS6 engines (0.05 to 0.08 ) to those for $3-4$ valved TS4 (0.07 to 0.15 ) and TS5 (0.11 to 0.17$)$ engines indicates that adopting overheadcamshaft 3-4 valve per cylinder engines is superior with regard to fuel efficiency improvements. Trends in the marketplace indicate that this statistical finding is consistent with what consumers and manufacturers have found with regard to these technologies, since turbocharged engines are now relatively rare, while the number of overhead-camshaft, 4-valve per cylinder engines continues to rise steadily. The NAS study cited estimates that the combination of overhead camshafts and 4-valves per cylinder would lead to a gain in efficiency of from 3.3 to $8.0 \%$ (based on adding the NAS percentages for the technologies separately). A comparison of the coefficients of TS5 and TS2 would lead to a very consistent estimate of a 9 to $10 \%$ gain. Note that this is very likely to be an overestimate because there are undoubtedly other efficiency-improving technologies packaged into the advanced vehicles in TS5 that we have not separately identified. The NAS study (Table B-1) did not give an estimate for the effect of turbocharging. This is consistent with the interpretation that this technology is no longer regarded as desirable.

Since there is only one example with a turbocharged fuelinjected, overhead-camshaft, 4-valve per cylinder engine (TS7), conclusions cannot be reliably drawn from it. Since the coefficients are much the same, on average, as those for TS5, the implication is that there is little efficiency advantage to 
adding a turbocharger after having gone to an overheadcamshaft, 4-valve per cylinder configuration.

Since the purpose of this paper is not to focus on engine technology, we do not present further detailed analysis of the engine technologies, although we have completed complex additional statistical analysis, a part of which is briefly discussed below. Note that the primary purpose of the engine technology information is to control for engine efficiency, not to estimate its magnitude. However, note that the TS coefficients are consistently positive and of a magnitude which is usually consistent with prior estimates. Allowing for the fact that the five driving cycles each represent meaningful information about engine efficiency, we estimated a pooled analysis of covariance model to develop "preferred" single estimates of the coefficients for the engine technologies (Ref. 21, Chap. 16). In the pooled regression model (not presented), the TS2 to TS7 engine technology set coefficients were consistently significantly different from TS 1 , (at the 0.01 probability level in five cases and at the 0.05 level in the TS4 case) and were often significantly different from one another. The preferred coefficients obtained are: 0.046 for TS2, 0.039 for TS3, 0.11 for TS4, 0.14 for TS5, 0.079 for TS6, and 0.15 for TS7. The EPA Highway coefficient was dummied out of the preferred TS4 estimate, and the CUCity coefficient was dummied out of the preferred TS7 estimate (using the multiplicative dummy technique used for the TArea variable). Given these results, it is clear that engine efficiency matters.

GEAR RATIO (or N/v) - An and Ross found that the $\mathrm{N} / \mathrm{v}$ ratio improved the behavior of their engineering model significantly. As noted, $\mathrm{N} / \mathrm{v}$ and top gear ratio are essentially statistically equivalent measures in this test, both giving almost identical results. The two variables in this statistical model which provide the greatest share of the explanatory power $\left(\mathrm{R}^{2}\right.$ total) are weight and gear ratio. The consistently high t-values for the two variables are an indirect indicator of this fact. Aside from the low and insignificant value for the CUCity cycle (where top gear may be used very little), the gear ratio elasticities do not exhibit a clear pattern, alternating between about -0.07 and -0.15 .

FRONTAL AREA - For frontal area, engineering theory (see Tables 1, 2, and 3) would suggest small insignificant coefficients on the city driving cycles, with rising and statistically significant coefficients for increasing average speeds. This result is obtained. The coefficient estimates for the two city cycles cannot be statistically distinguished from zero. The two highway coefficients are significant and identical, at 0.29 . Consistent with engineering theory, the value for steady highway speed is largest, at 0.42 . Consistent with the enginecring models shown in Tables 1 to 3 , as the estimated elasticity of aerodynamics increases, the estimated elasticity lor weight decreases. Largely consistent with the engineering models, the sum of the weight and area coefficients remains near, but generally below, 1.0. On the other hand, for the two driving cycles where direct comparisons of estimates are possible (the EPA cycles), the elasticity estimates for weight are well above those implied by the engineering models, and the elasticity estimates for frontal area are well below.

For the differential effects of pickup trucks and sport utility vehicles - presumed to be due to a significantly different $\mathrm{C}_{\mathrm{d}}$ - there is also a clear, theoretically correct rise in the magnitude of coefficients as average speed rises, with the statistical certainty of a difference becoming most clear under the same driving cycles as for the Area coefficients. When tested separately (not presented), the shape of minivans was not estimated to be any more or less derodynamically efficient than that for passenger cars (though they were clearly more aerodynamically efficient than the other trucks), so minivans were grouped with passenger cars. The magnitudes of the frontal area coefficients were more consistent with theory and more easily statisiically significant when minivans were included with passenger cars. The high frontal area of vans relative to passenger cars improved the range of the frontal area observations of the passenger car sample, allowing better statistical resolution of the effects of frontal area.

TRANSMISSION - The coefficient of the automatic transmission dummy variahle implies that stick transmissions are more efficient than automatic transmissions. Unfortunately, from an energy efficiency perspective, the preference for an automatic leads to lower fuel economy. The largest negative effect on fuel economy due to an automatic transmission was estimated to occur in the CUCity driving cycle, but this was not reflected in the EPA Urban cycle estimate.

ROLLING RESISTANCE - Unfortunately, the only information available on tires was for dimensional specifications. We did not have any measure of rolling resistance. We conducted some experiments using a ruler on cars in parking lots and determined that the length of tire tread on the road was very highly correlated with the weight of the vehicle. Since weight was already in the equation, length of tire on the road would not be useful. We did find that there was significant variation in the width of tire surface touching the road. We found that this is highly correlated with tire aspect ratio (P), after the effects of length of tread on the road are taken into account. Our reasoning was that the effort to lay more rubber on the road for handling purposes should lead to greater rolling friction. Thus, our hypothesis was that aspect ratio would have a negative effect on fuel economy. Statistically, we found the opposite effect, at least for the three $\mathrm{CU}$ tests. We note that this variable is estimated to have a clear statistically significant effect in on-road tests but not in dynamometer tests. There is some logic to finding a difference between dynamometer and on-road tests, since the nature of tire contact is different for the rollers on dynamometers than for tread on highway surfaces. We checked for one possible explanation for the significance of $\mathrm{P}$ - that there would be a positive aerodynamic effect of low road clearance. For a given wheel diameter (which we found to be highly correlated with weight), a higher aspect ratio causes the car to sit lower to the ground. We collected road-clearance data and tested its effect, finding that it was insignificant. Another interpretation of the elasticity estimates for $\mathrm{P}$ is the possibility of correlation with low drag vehicles; the vehicles with high-aspect-ratio tires may be performance vehicles designed to have low drag coefficients. However, the possibility that we suspect is that newer tire designs, which likely have lower rolling resistance, were also designed to have a higher aspect ratio. We noticed that later model tires have higher aspect ratios. Further, the rise in the coefficients from the city cycle to the higher speed ciriving conditions is relatively moderate, consistent with the engineering predictions of Sovran (Table 3). Also, we note that, if changes in aspect ratio are highly correlated with changes in rolling resistance, the size of the coefficients obtained should in the neighborhood of those predicted by Sovran, and that is the case. Most likley, flexible sidewalls are associated with low rolling resistance and low tire profiles (i.e., high aspect ratios). Since rolling resistance is also 
affected by road conditions, there is no basis to assure that rolling resistance should rise steadily with speed in the Consumers Union tests, since the road conditions for each test are different. Consequently, no meaning should be attached to the drop in the CU88kph coefficient with respect to the CUHighway coefficient.

GOODNESS-OF-FIT - As in the case of Berger, Smith and Andrews (27), we find that the measures of goodness of fit $\left(\mathrm{R}^{2}\right)$ of the regressions are relatively large, ranging here from 0.82 to 0.92 . As mentioned previously, we found that the In-Ir formulation gave better fits and had better properties of the residuals than did analogous linear models. Weight is a dominant variable with respect to determination of the $R^{2}$ value. The correlation of weight and fuel economy is highest for the city cycles, at 0.94 (CU) and 0.92 (EPA), dropping to 0.89 (CU) and 0.81 (EPA) for the highway cycles, and then to 0.76 for the steady $88 \mathrm{~km} / \mathrm{h}$ speed. Weight is very accurately measured, while drag area $\left(C_{d}\right.$ times Area) is imprecisely measured, since $C_{d}$ is unknown and frontal area was approximated. Thus, since the role of drag area increases in the highway and $88 \mathrm{~km} / \mathrm{h}$ steady speed driving cycles respectively, it is not surprising that the $\mathrm{R}^{2}$ declines for the latter regressions.

\section{CONCLUSIONS}

The larger (smaller) statistical elasticity estimates for the influence of weight (drag area) on fuel economy than derived from engineering models requires explanation. An obvious part of the explanation is that the idle fuel flow rate is systematically related to weight of the vehicle, when the design goal is to hold performance constant. Performance, in terms of 0 to $97 \mathrm{~km} / \mathrm{h}$ acceleration, is almost completely explained by peak power per kilogram (17). Once engine technology is held constant (or, in the equations used here, controlled for), the only way to keep power per kilogram constant is to vary engine vulume. In our data set ln of engine volume, at a value of 0.88 , was correlated more highly with in of weight than were any other pair of independent variables. Engine volume did not prove significant in tests in our equations, presumably because its influence was already accounted for through its correlation with weight. Sovran noted "an approximately linear variation of fuel rate with engine displacement", wh.' ${ }^{\prime}$. An and Ross explicitly wrote that idle fuel consumption is a func:ion of engine volume. Neither treated engine volume as a functio: of vehicle weight. If one were to rewrite EQ (2) such that idling and braking are also linear functions of mass, then the solution for the "correct" elasticity of response of fuel consumption (inverse of fuel economy) to weight would increase to 0.70 , a value much closer to the statistically estimated 0.95 for the EPA City cycle. Generalizing, the Sovran highway estimate would increase to 0.34 , slightly closer to the statistically estimated value. If aerodynamics of passenger cars in 1986-1988 were $30 \%$ better than assumed by Sovran, the revised Sovran-based urban total would increase to 0.75 and the highway value would increase to 0.42 . Note that the "right" coefficients can only be estimated through a restructuring of the Sovran model, since those in Table 3 would be sensitive to the assumed changes in the relationship of idling and braking energy use to vehicle mass. Ih, the case of the use of the An and Ross model, the procedure discussed above would also close the gap between the engineering estimates of the response of fuel consumption to weight. An and Ross recognized this, stating that their estimates of response of fuel consumption to weight would be increased if engine size were varied to hold performance constant. However, they did not estimate the magnitude of the effect.

It is possible, in fact, that accessory loads for such accessories as power steering and power brakes are also linked to weight. A proper engincering model of the influence of weight on fuel consumpition in vehicles with performance held constant (including acceleration, braking pedal effort, and turning force for steering wheels) will undoubtedly close the gap between the value of weight implied in current engineering models and that implied in statistical models, such as those presented here and elsewhere by Berger, Smith and Andrews. It is recognized, however, if performance is not held constant, and an estimate of the effect of weight reduction in an existing vehicle with a constant displacement and technology engine and with unchanging accessories is desired, the existing engineering models may suffice.

For those working on long-term assessments of the ability of using light-weight materials to help enable electric and hybrid vehicles to beat the contemporary internalcombustion-engine (ICE) vehicle, care must be exercised in the projections of the degree of ability to improve the competition (i.e. the ICE vehicle) through the use of the same lightweight materials. 'This analysis suggests that current engineering models are likely to underestimate the gains from weight reduction and should be reexamined in this regard. Reinforcing this assertion is the fact that this paper's crude estimates of adding effects of weight as a determinant of idling and braking energy consumption in engineering models will increase the estimated benefit of weight reduction, and increase it by a greater amount in urban driving than in highway driving. This could tend to offset somewhat the current engineering estimates of comparative advantage (vs. the ICE vehicle) of electrics and hybrids, whose energy consumption advantages are more pronounced in urban driving conditions (see Wang and Santini [11] for a discussion of these effects for electric vehicles).

Clear weaknesses of the information used in the statistical models existed for the proxy variables used to estimate effects of drag area and rolling resistance. Better measures for these variables could bring the statistically estimated coefficients of weight down slightly.

\section{ACKNOWLEDGMENTS}

We thank Dr. Phil Patterson, our project officer, for support of the "Transportation Projection and Assessment" research project under which this research has been conducted. Work sponsored by the U.S. Department of Energy, Assistant Secretary for Energy Efficiency and Renewable Energy, Office of Transportation Technologies, under contract W-31-109-Eng38. We would also like to thank three anonymous referees for helpful suggestions. Any errors in analysis or interpretation are, however, our own.

\section{REFERENCES}

1. National Research Council, 1992, Automotive Fuel Economy: How Far Should We Go?, National Academy Press, Washington, DC.

2. Sovran, G., and M.S. Bohn, 1981, "Formulae for the Tractive Energy Requirements of Vehicles Driving the EPA Schedules," SAE Paper 8101084, SAE International, Warrendale, PA. 
3. Sovran, G., 1983, "Tractive-Energy-Based Formulae for the Impact of Aerodynamics on Fuel Economy Over the EPA Driving Schedules," SAE Paper 830304, SAE International, Warrendale, PA.

4. An, F., 1992, Automobile Fuel Economy and Traffic Congestion, PhD. Dissertation, Department of Applied Physics, University of Michigan, Ann Arbor, MI.

5. An, F., and M. Ross, 1993, "A Model of Fuel Economy and Driving Patterns," SAE Paper 930328, SAE International, Warrendale, PA.

6. Hanks, J.W., and T.J. Lomax, 1989, Roadway Congestion in Major Urban Areas, Federal Highway Report FHWA/TX-90-1131-2, Texas Transportation Institute, College Station, TX.

7. Chelimsky, E., 1991, Traffic Congestion: The Need and Opportunity for Federal Involvement, U.S. General Accounting Office Testimony GAO/T-PEMD-91-10, Washington, DC, May 29.

8. Cameron, M., 1991, Transportation Efficiency: Tackling Southern California's Air Pollution and Congestion, Regional Institute of Southern California, Berkeley, CA.

9. Watterson, W., 1991, "Linked Simulation of Land Use and Transportation Systems," presented at the Conference on Transportation and Global Climate Change: LongRun Options, sponsored by U.S. Environmental Protection Agency, U.S. Department of ènergy: and U.S. Department of Transportation, held at Pacific Grove, Calif Aug. 25-28.

10. White, R.E., et al., 1991, Smart Highways, U.S. General Accounting Office Report GAO/PEMD-91-18, Washington, DC.

11. Wang, Q., and D. Santini, 1993, "Magnitude and Value of Electric Vehicle Emissions Reductions for Six Driving Cycles in Four U.S. Cities with Varying Air Quality Problems," Paper 930526 presented at the 72nd Annual Meeting of the Transportation Research Board, Washington, DC, Jan. 10-14.

12. Wicks, 1991, "Development of a Model to Predict Electric Vehicle Performance over a Variety of Driving Conditions" and "Potential Benefits from Applying Electric Vehicle Technology to Engine Driven Vehicles," Proceedings of the 27th Intersociety Energy Conversion Engineering Conference, San Diego, CA, Aug. 5.

13. Fwa, T., and B. Ang, 1992, "Estimating Automobile Fuel Consumption in Urban Traffic," Transportation Research Record 1366, Transportation Research Board, National Research Council, Washington, DC.

14. Murrell, D., 1980, Passenger Car Fuel Economy: EPA and Road, EPA Report EPA/3-80-010, Ann Arbor, MI.
15. MacCready, P., 1991, "Electric and Hybrid Vehicles," presented at the Conference on Transportation and Global Climate Change: Long-Run Options, sponsored by U.S. En rironmental Protection Agency, U.S. Department of Energy, and U.S. Department of Transportation, held at Pacific Grove, CA, Aug. 25-28.

16. Heavenrich, R.M., J.D. Murrell, and K.D. Hellman, 1991, Light Duty Automotive Technology and Fuel Economy Trends Through 1991, U.S. EPA Report EPA/AA/CTAB/91-02, Office of Mobile Sources, Ann Arbor, MI.

17. Young, Y.R., 1991, Regression Analysis for Performance of Light Duty Vehicles, National Highway Traffic Safety Administration Report DOT HS 807 763, National Highway Traffic Safety Administration, Washington, DC.

18. Markovich, 1989, Used Car Buying Guide 1989, Consumers Union, Mount Vernnn, NY.

19. Consumers Union, 1993, Consumer Reports: The Annual Auto Issue, Yonkers, NY.

20. Austin, T.G., et al., 1992, "An Analysis of Driving Patterns in Los Angeles During 1992," presented at the 3rd Annual CRC-APRAC On-Road Vehicle Emissions Workshop, sponsored by California Air Resources Board, Sacramento, CA, Dec. 3.

21. Cleary, J., and H. Levenbach, 1982, The Professional Forecaster, Lifetime Learning Publications, Belmont, CA.

22. Chilton Book Co., 1989, Chilton's Auto Repair Manual 1983-1990, Radnor, PA.

23. Chilton Book Co., 1989, Chilton's Import Car Repair Manual 1983-1990, Radnor, PA.

24. Automotive News, 1986, 1986 Market Data Book. No. 5125, Crain Publications, Detroit, MI, pp. 37-50.

25. Automotive News, 1987, 1987 Market Data Book. No. 5178, Crain Publications, Detroit, MI, pp. 57-70.

26. Automotive News, 1988, 1988 Market Data Book. No. 5235, Crain Publications, Detroit, MI, pp. 41-53.

27. Berger, J.O., M.H. Smith, and R.W. Andrews, 1990, "A System for Estimating Fuel Economy Potential due to Technology Improvements," presented at the workshop of the Committce on Fuel Economy of Automobiles and Light Trucks, Irvine, CA, July 8-12, University of Michigan, Ann Arbor, MI. 
Table 1. Height Loss in a Kilometer to Make up for Energy Loss for Three Average "Cycle" Speeds

\begin{tabular}{|l|l|c|c|c|}
\hline \multicolumn{2}{|c|}{} & \multicolumn{3}{l|}{ Height Loss at Average "Cycle" Speed (m) } \\
\hline & $24 \mathrm{~km} / \mathrm{h}$ & $48 \mathrm{~km} / \mathrm{h}$ & $97 \mathrm{~km} / \mathrm{h}$ \\
\hline & Number of stops per kilometer & & & \\
\hline & Total seconds to go a kilometer & 3.1 & 0.9 & 0 \\
\hline & Cruise seconds to go a kilometer & 149 & 75 & 37 \\
\hline & Implied cruise speed (km/h) & 103 & 60.6 & 37 \\
\hline & Kinetic loss per stop from cruise (m) & 5.1 & 14.5 & 38.2 \\
\hline & & & & \\
\hline \multicolumn{2}{|l|}{ Time on road or stop delay related losses (m) } & & & \\
\hline & Idling loss @ 0.08 m/s for idling only & 5.95 & 1.78 & 0 \\
\hline & Accessory loss @ 0.055 m/s - total trip & 13.2 & 6.59 & 3.29 \\
\hline Vehicle weight related losses (m) & & & \\
\hline & Rolling friction & 11 & 11 & 11 \\
\hline & Total kinetic Loss & 25.2 & 21.7 & 0.0 \\
\hline Body snape and size related losses (m) & & & \\
\hline & Aerodynamic drag at cruise & 4.23 & 12.1 & 32.0 \\
\hline & & & & \\
\hline Sum of losses per mile (m) & 59.9 & 53.4 & 46.6 \\
\hline & & & & \\
\hline Losses expressed as a percentage of total losses & & & \\
\hline & Time on road or delayed related losses & $32 \%$ & $16 \%$ & $7 \%$ \\
\hline & Vehicle weight related losses & $61 \%$ & $61 \%$ & $24 \%$ \\
\hline & Aerodynamic drag at cruise & $7 \%$ & $23 \%$ & $69 \%$ \\
\hline
\end{tabular}

Source: Adapted from reference 15, Table 1.

Table 2. Share of Energy Losses due to Components of Several Driving Cycles, before Engine Friction Losses

\begin{tabular}{|l|c|c|c|c|c|c|c|}
\hline & New York & Japan & Europe & Beijing & Melbourne & $\begin{array}{c}\text { EPA } \\
\text { Urban }\end{array}$ & $\begin{array}{c}\text { EPA } \\
\text { HWY }\end{array}$ \\
\hline & & & & & & & \\
\hline Average speed $(\mathrm{km} / \mathrm{h})$ & 11.4 & 17.4 & 18.8 & 19.6 & 30.4 & 31.5 & 77.6 \\
\hline & & & & & & & \\
\hline Time related losses & $51 \%$ & $44 \%$ & $48 \%$ & $41 \%$ & $25 \%$ & $27 \%$ & $8 \%$ \\
\hline Weight related losses & $47 \%$ & $51 \%$ & $48 \%$ & $56 \%$ & $62 \%$ & $59 \%$ & $46 \%$ \\
\hline Aerodynamic drag losses & $2 \%$ & $5 \%$ & $5 \%$ & $3 \%$ & $13 \%$ & $14 \%$ & $46 \%$ \\
\hline
\end{tabular}

Source: Adapted from reference 5, Table 9.

Table 3. Fuel Consumption Fractions for the Vehicle Type Estimated by Sovran (3)

\begin{tabular}{|l|c|c|c|c|c|c|}
\hline \multicolumn{1}{|c|}{ Cycle } & $\begin{array}{c}\text { Kinetic } \\
\text { Energy } \\
\text { Gain }\end{array}$ & $\begin{array}{c}\text { Rolling } \\
\text { Resistance }\end{array}$ & $\begin{array}{c}\text { Aero- } \\
\text { dynamic } \\
\text { Drag }\end{array}$ & $\begin{array}{c}\text { Accessory } \\
\text { Loads }\end{array}$ & Idling & Braking \\
\hline $\begin{array}{l}\text { EPA } \\
\text { Urban }\end{array}$ & 0.37 & 0.17 & 0.20 & 0.10 & 0.07 & 0.09 \\
\hline $\begin{array}{l}\text { EPA } \\
\text { Highway }\end{array}$ & 0.10 & 0.22 & 0.57 & 0.09 & 0.00 & 0.02 \\
\hline
\end{tabular}


Table 4. Results of the Regression Model by Driving Cycle

\begin{tabular}{|c|c|c|c|c|c|}
\hline & In (CU City) & In (EPA City) & $\begin{array}{l}\text { In (EPA) } \\
\text { Highway) }\end{array}$ & $\begin{array}{c}\ln (\mathrm{CU} \\
\text { Highway) }\end{array}$ & In (CU88kph) \\
\hline Ave. sample $\mathrm{km} / \mathrm{L}$ & 7.36 & 9.48 & 11.8 & 12.4 & 14.7 \\
\hline \multicolumn{6}{|l|}{ Variable Coeff. } \\
\hline Intercept $\left(a_{0}\right)$ & $\begin{array}{c}7.77 \\
(12.7)^{* * *}\end{array}$ & $\begin{array}{c}-8.82 \\
(12.3)^{* * *}\end{array}$ & $\begin{array}{c}8.50 \\
(13.5)^{* * *}\end{array}$ & $\begin{array}{c}7.18 \\
(10.7)^{* * *}\end{array}$ & $\begin{array}{l}6.69 \\
(9.55)^{* * *}\end{array}$ \\
\hline In (Weight) (a $\left.a_{1}\right)$ & $\begin{array}{l}-0.76 \\
(-9.92)^{* * *}\end{array}$ & $\begin{array}{c}-0.95 \\
(-10.7)^{* * *} \\
\end{array}$ & $\begin{array}{l}-0.72 \\
(-9.22)^{* * *}\end{array}$ & $\begin{array}{l}-0.65 \\
(-7.66)^{* * *}\end{array}$ & $\begin{array}{c}-0.49 \\
(-5.54)^{* * *}\end{array}$ \\
\hline $\ln ($ power/kg) (a) & $\begin{array}{c}-0.05 \\
(-0.97) \\
\end{array}$ & $\begin{array}{c}-0.30 \\
(-4.81)^{* * *} \\
\end{array}$ & $\begin{array}{c}-0.26 \\
(-4.61)^{* * *}\end{array}$ & $\begin{array}{l}-0.13 \\
(-2.16)^{* *} \\
\end{array}$ & $\begin{array}{c}-0.23 \\
(-3.66)^{* * *} \\
\end{array}$ \\
\hline TS2 $\left(a_{3}\right)$ & $\begin{array}{c}0.06 \\
(1.54)\end{array}$ & $\begin{array}{c}0.05 \\
(1.03)\end{array}$ & $\begin{array}{c}0.02 \\
(0.36) \\
\end{array}$ & $\begin{array}{c}0.07 \\
(1.56) \\
\end{array}$ & $\begin{array}{c}0.03 \\
(0.69) \\
\end{array}$ \\
\hline TS3 (a4) & $\begin{array}{c}0.02 \\
(0.55) \\
\end{array}$ & $\begin{array}{c}0.04 \\
(0.94) \\
\end{array}$ & $\begin{array}{l}0.10 \\
(2.50)^{* * *} \\
\end{array}$ & $\begin{array}{c}0.06 \\
(1.39) \\
\end{array}$ & $\begin{array}{c}0.05 \\
(1.08) \\
\end{array}$ \\
\hline TS4 (as) & $\begin{array}{l}0.12 \\
(1.91)^{*}\end{array}$ & $\begin{array}{c}0.12 \\
(1.63) \\
\end{array}$ & $\begin{array}{r}0.07 \\
(1.07) \\
\end{array}$ & $\begin{array}{c}0.10 \\
(1.50) \\
\end{array}$ & $\begin{array}{l}0.15 \\
(2.05)^{* *} \\
\end{array}$ \\
\hline TS5 (a6) & $\begin{array}{l}0.15 \\
(3.18)^{* * *} \\
\end{array}$ & $\begin{array}{l}0.14 \\
(2.58)^{* * *} \\
\end{array}$ & $\begin{array}{c}0.11 \\
(2.19)^{* *} \\
\end{array}$ & $\begin{array}{l}0.17 \\
(3.18)^{* * *} \\
\end{array}$ & $\begin{array}{c}0.13 \\
(2.26)^{* *} \\
\end{array}$ \\
\hline TS6 $\left(a_{7}\right)$ & $\begin{array}{c}0.08 \\
(1.54) \\
\end{array}$ & $\begin{array}{c}0.08 \\
(1.41) \\
\end{array}$ & $\begin{array}{c}0.05 \\
(1.01) \\
\end{array}$ & $\begin{array}{c}0.08 \\
(1.35) \\
\end{array}$ & $\begin{array}{c}0.08 \\
(1.23) \\
\end{array}$ \\
\hline TS7 $\left(a_{8}\right)$ & $\begin{array}{c}-0.03 \\
(-0.43) \\
\end{array}$ & $\begin{array}{c}0.12 \\
(1.31) \\
\end{array}$ & $\begin{array}{l}0.17 \\
(2.14)^{* *} \\
\end{array}$ & $\begin{array}{c}0.16 \\
(1.87)^{*}\end{array}$ & $\begin{array}{c}0.17 \\
(1.82)^{*}\end{array}$ \\
\hline Automatic (ag) & $\begin{array}{l}-0.11 \\
(-5.22)^{* * *}\end{array}$ & $\begin{array}{c}-0.03 \\
(-1.24) \\
\end{array}$ & $\begin{array}{l}-0.05 \\
(-2.52)^{* * *}\end{array}$ & $\begin{array}{l}-0.04 \\
(-1.82)^{*}\end{array}$ & $\begin{array}{l}-0.06 \\
(-2.75)^{* * *}\end{array}$ \\
\hline $\begin{array}{c}\text { In(Gear Ratio) } \\
\left(a_{10}\right) \\
\end{array}$ & $\begin{array}{c}-0.01 \\
(-0.60) \\
\end{array}$ & $\begin{array}{c}-0.08 \\
(-3.86)^{* * *} \\
\end{array}$ & $\begin{array}{c}-0.15 \\
(-8.06)^{* * *} \\
\end{array}$ & $\begin{array}{l}-0.07 \\
(-3.68)^{* * *}\end{array}$ & $\begin{array}{l}-0.15 \\
(-7.10)^{* * *}\end{array}$ \\
\hline $\begin{array}{c}\text { In(Frontal Area) } \\
\left(a_{11}\right) \\
\end{array}$ & $\begin{array}{c}-0.18 \\
(-1.50) \\
\end{array}$ & $\begin{array}{c}0.01 \\
(0.08) \\
\end{array}$ & $\begin{array}{c}-0.29 \\
(-2.42)^{* *}\end{array}$ & $\begin{array}{c}-0.29 \\
(-2.21)^{* *}\end{array}$ & $\begin{array}{l}-0.42 \\
(-3.02)^{* * *} \\
\end{array}$ \\
\hline $\begin{array}{l}\text { In (Pickup Sport } \\
\text { UtilityArea) }\left(\mathrm{a}_{12}\right)\end{array}$ & $\begin{array}{c}-0.01 \\
(-1.22) \\
\end{array}$ & $\begin{array}{c}-0.02 \\
(-1.73)^{*}\end{array}$ & $\begin{array}{c}-0.04 \\
(-4.01)^{* * *}\end{array}$ & $\begin{array}{l}-0.04 \\
(-3.92)^{* * *}\end{array}$ & $\begin{array}{l}-0.05 \\
(-4.62)^{* * *} \\
\end{array}$ \\
\hline $\begin{array}{r}\text { In (Tire Aspect } \\
\text { Ratio) }\left(a_{13}\right) \\
\end{array}$ & $\begin{array}{c}0.16 \\
(1.85)^{*}\end{array}$ & $\begin{array}{c}0.02 \\
(0.24) \\
\end{array}$ & $\begin{array}{c}0.04 \\
(0.50) \\
\end{array}$ & $\begin{array}{l}0.27 \\
(2.86)^{* * *} \\
\end{array}$ & $\begin{array}{l}0.22 \\
(2.19)^{* *} \\
\end{array}$ \\
\hline Adjusted $\mathrm{R}^{2}$ & 0.92 & 0.88 & 0.87 & 0.86 & 0.82 \\
\hline
\end{tabular}

*** Statistical significance at the 0.01 probability level.

** Statistical significance at the 0.05 probability level.

- Statistical significance at the 0.10 probability level. 

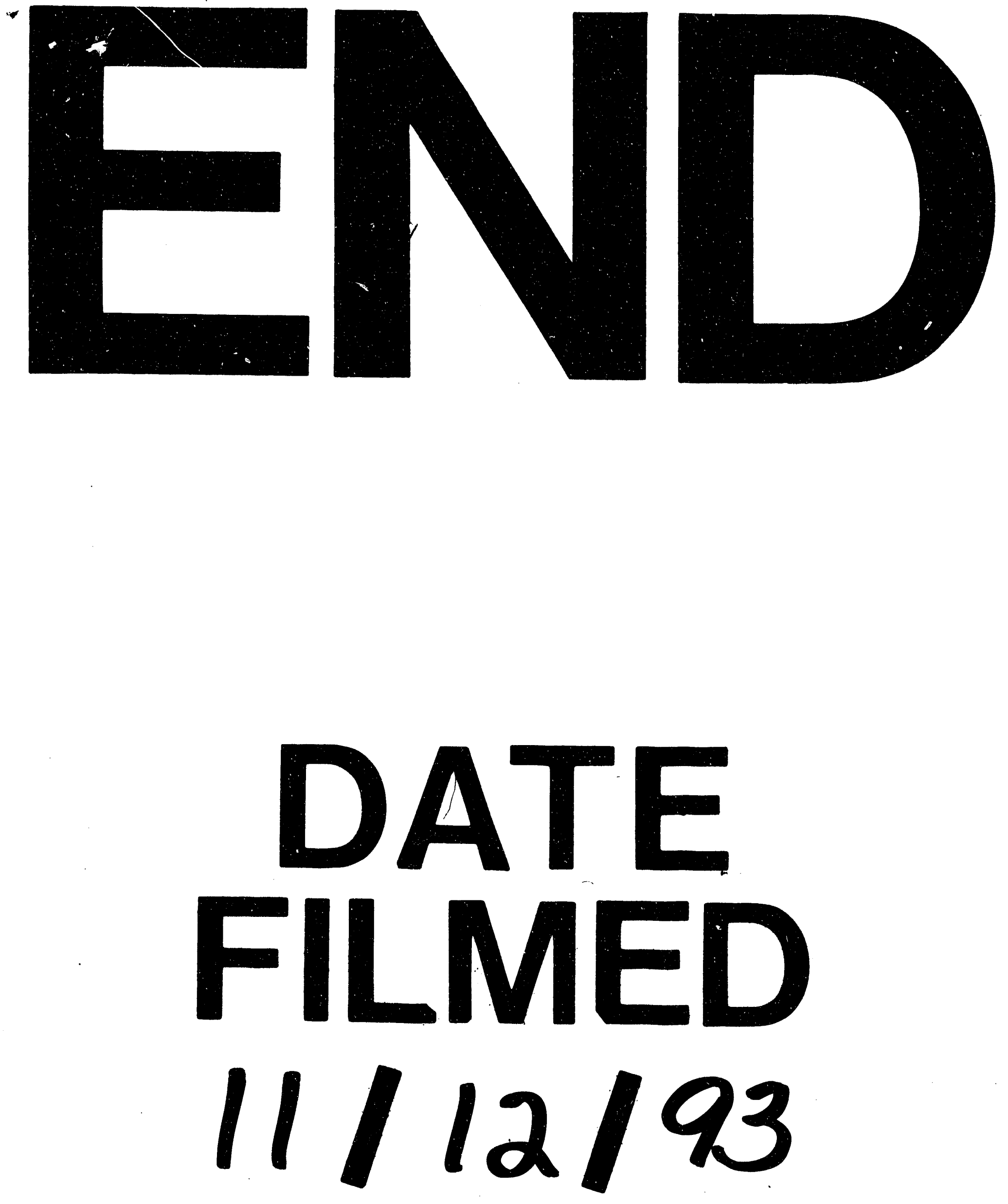


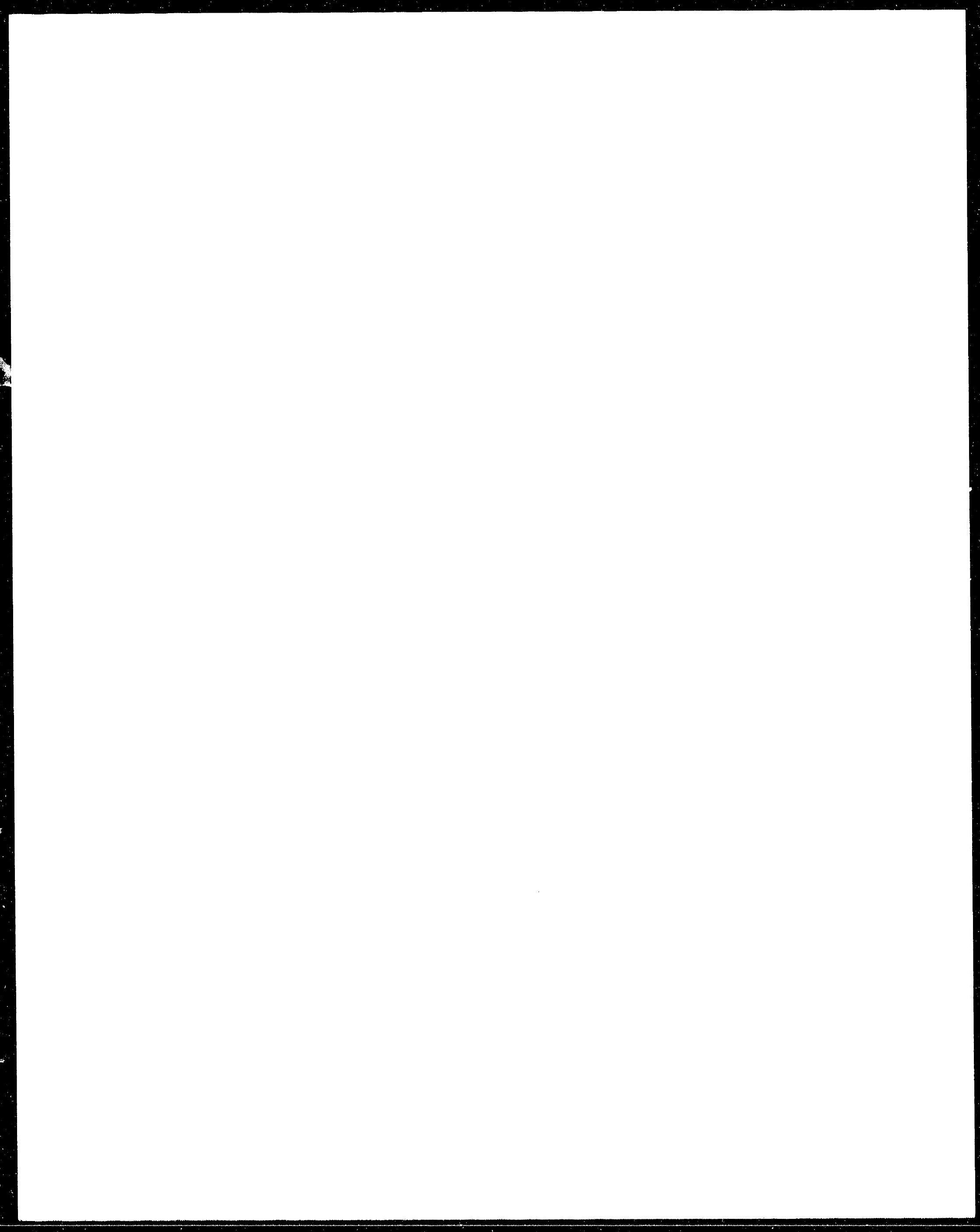

